\title{
The Mars Homestead: a Mars Base Constructed from Local Materials
}

\author{
Bruce Mackenzie \\ Mars Foundation, BMackenzie@alum.mit.edu, 781-944-7027, \\ 102 Sanborn Ln. Reading, MA 01867-1009, USA \\ Bart Leahy \\ BLeahy@MarsHome.org,Huntsville,AL, USA \\ Georgi Petrov \\ GPetrov@alum.mit.edu,Boston MA,USA \\ Gary Fisher \\ GaryF@MarsHome.org, P.O. Box 694, Bryn Athyn, PA 19009
}

The Mars Homestead ${ }^{\mathrm{TM}}$ project is a detailed design the first permanent Mars settlement built primarily from local resources. A very early, permanent base can support scientific investigations more cost effectively and safer then a series of round-trip missions, because about half of the mission cost can be saved by eliminating most return spacecraft, fuel manufacture, and consumables.

Instead of focusing on how a single technology can be applied, we look at the broad view of all the needed structures and materials to construct an initial base and growing settlement. We concentrate on the materials and architectural design of the first phase of development which will support 12 persons.

A preliminary design, the "Hillside Base", has been completed. We assume that 12 people will deploy, bootstrap, and maintain small, semi-automated refining and manufacturing facilities. Using locally produced fiberglass, metal, ceramics, and simple plastics, they then construct permanent quarters for themselves. This Hillside Base includes living quarters, workshops, greenhouses, maintenance facilities, waste processing, refining, manufacturing, and other areas needed to live and work. After they move into their completed quarters, they continue construction for an additional dozen people, mostly scientists, who arrive about every two and a half years. The base grows into a permanent manufacturing settlement, producing equipment for additional scientific outposts and other permanent settlements.

We welcome participation by everyone. Small, Earth based technical projects can build public interest in permanent settlement of space. Testing of key technologies is being planned with the goal to construct a full-scale terrestrial analog for testing and public demonstration of construction strategies. The Mars Homestead Project is a key project of the Mars Foundation ${ }^{\mathrm{TM}}$. It is a young non-profit, 501(c)(3) organization dedicated to establishing permanent, thriving settlements beyond the Earth, starting with Mars. See www.MarsHome.org . 


\section{Introduction - The Mars Homestead Project}

The Mars Homestead ${ }^{\mathrm{TM}}$ project is to plan a sequence of Mars Bases built from local materials, leading to permanent settlement of Mars and the Solar System. The initial study was by a small team of volunteers who met via Internet and telephone, with periodic in-person meetings at the Massachusetts Institute of Technology. Rather than studying one technology, the team identified a set of multiple technologies and materials that are nessesary to construct a base. The result is the "Hillside Base" design illustrated in Figure 1, to be built by 12 people with semi-automated equipment. ${ }^{1}$

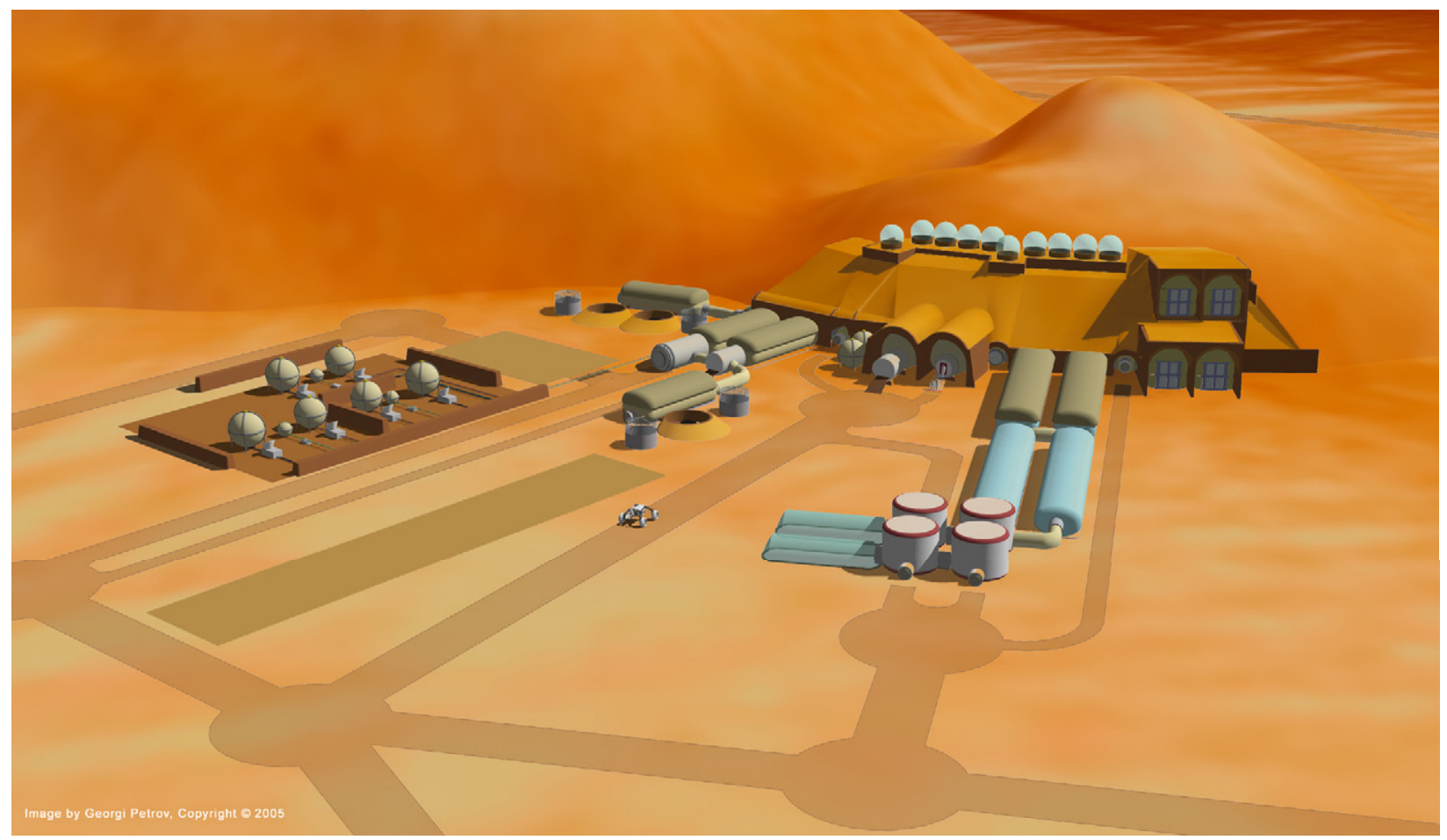

Figure 1. Hillside Base design, gas plant and manufacturing area on left is brought from Earth, to construct the majority of the base from local materials.

The Mars Homestead Project is the first project of the Mars Foundation ${ }^{\mathrm{TM}}$, a non-profit, 501(c)(3) organization. Our long-term vision is that there will be numerous human settlements throughout space, including among the asteroids and in orbital "O'Neill" settlements. These will provide resources, opportunities, and security for our descendents and the expansion of the domain of life, far beyond what our limited size Earth can provide. Our mission is to show the advantages of an early base on Mars, and then establish such a base which can grow into a Mars Settlement.

The basic assumption of the Project is that human Mars settlement need not wait until after extensive exploration. Exploration can best be facilitated —and supported—by building a permanent habitation there. That is, exploration and settlement can be done simultaneously. The experience gained by building the Mars Settlement, especially in semi-closed life support and Earth-Mars transportation, will open the solar system to humanity. To that end, the Project 
continues to identify ways to create a viable, sustainable, and pleasant community in isolation under extreme conditions.

A permanent settlement must, to some extent, be self-sufficient once it is established. In order to become self-sufficient, the settlement must incorporate many of the activities required to sustain any civilization on Earth: people, habitats, mineral and metal resources, and eventually families, food, commerce, and culture.

The members of the Mars Foundation are well aware that other technologies are just as critical to getting us to Mars; however, we have chosen to focus our attention on the technological, social, and environmental fundamentals that will be necessary once humans arrive there. The study concentrates especially on the technologies needed for the first construction, which many people assume would be too in the far future to seriously consider.

\section{Identifying Key Technologies and Social Structures for Living on Mars}

Any task as massive and difficult as exploring and settling Mars requires advance planning, development, and other efforts to literally and figuratively "get off the ground.” These steps include feasibility studies, prototype projects, operational and environmental research, identifying funding sources, hardware development, and preliminary exploration. The Foundation has already taken the first step by developing a program feasibility study and-like NASA, though with a different emphasis — a design reference mission. The Mars Homestead Project-our feasibility study - began by identifying the basic mission of a Mars settlement and the primary challenges involved in building such a habitat.

\section{A. Purposes for and Challenges to a Mars Settlement}

The Mars Homestead Project began with a simple operational premise: to establish a permanent base on Mars to perform high-value scientific and engineering research and to grow this outpost into a larger, permanent settlement. This vision includes:

- Testing manufacturing methods in order to use Mars resources to support human life.

- $\quad$ Searching for past and present life on Mars.

- Conducting basic science research to gain new knowledge about the solar system's origin and history.

- Performing applied science research in order to use Mars resources to support human life.

The challenges of conducting such work are daunting, not least upon the individuals who must first set foot on the Red Planet.

Max Flexibility vs. Mass Production

Much like a small village in medieval Europe, the first Mars settlement will face slow and limited communications with the outside world. This will require a great deal of self-sufficiency in developing basic tools and structures needed to survive. Unable to import an entire factory or 
production line capable of mass-producing low-cost utility items, Martian settlers will necessarily have to make many of their own tools in small lot sizes.

This situation will require flexible small-scale manufacturing and creative engineers skilled machinists capable of both high-tech and low-tech manufacturing-the equivalent of medieval blacksmiths.

\section{Worker Productivity}

Because the first crews to Mars will most likely be small-growing from 4 to 8 to 12 people initially - the crew must, of necessity, comprise individuals capable of multitasking in a variety of disciplines, including civil engineering, life support systems, medical science, botany, microbiology, mechanical engineering, laboratory science, and, especially, simple mechanical tinkering. Such multitasking necessarily implies high worker productivity and proficiency across multiple disciplines. Illnesses or possible deaths will leave the crew short of vital skills and will necessarily result in emotional and social strain among the crew, though obviously they will have support from experts on Earth. This support would include redesigning equipment on Earth, and transmitting the new equipment designs to be manufactured on Mars.

\section{Limited Earth-Mars Transportation}

Many high-technology items will need to be flown to Mars from Earth, such as nuclear reactors and specialized laboratory equipment. The settlers will need to be able to manufacture low-technology, high-mass materials (e.g. bricks, Fiberglas, or iron) on Mars. We assume no radical advances in propulsion systems in the near future, or, if there are advances in propulsion, they will be used to reduce the cost rather than to increase the mass of equipment delivered to Mars. In addition, the relative positions of Earth and Mars dictate that supply flights only occur during the launch windows every two Earth years. Such potential delays mean that several fundamental requirements must be met:

- Earth-Mars cargo support flights must be restricted to high-cost, high-technology equipment that cannot be produced locally.

- Mission-critical equipment sent from Earth must be highly reliable.

- If any high-technology equipment from Earth breaks down, it must be reparable by the crew on-site.

- The crew must have a robust capability to manufacture simple but necessary materials or equipment on-site.

\section{Unknowns}

While any exploration or settlement crew is unlikely to encounter dragons or hostile natives, they will still have to cope with unexpected challenges related to the interaction between people,

the equipment and the Martian environment. Such unknowns will impact settlers' efforts to adapt Earth-based mining, refining, and manufacturing to Mars, the safety and reliability of equipment, and the overall cost of establishing the settlement. 


\section{Overcoming Engineering Constraints on Mars}

Mars presents any future builders with a variety of very serious challenges and constraints from near-vacuum atmospheric conditions to subzero temperatures lower than anything experienced on Earth. Table 1 below summarizes some of the highlights between the two planets.

\begin{tabular}{|l|l|l|}
\hline $\begin{array}{l}\text { Average Distance from } \\
\text { Sun }\end{array}$ & \multicolumn{1}{|c|}{ Earth } & \multicolumn{1}{c|}{ Mars } \\
\hline Diameter & $12,756 \mathrm{~km}$ & 225 million km \\
\hline Axial Tilt & $23.5^{\circ}$ & $6,786 \mathrm{~km}$ \\
\hline Length of Year & 365.25 Earth Days & $25^{\circ}$ \\
\hline Length of Days & 24 hours & 687 Earth Days \\
\hline Gravity & $1 \mathrm{~g}$ & 24 hours 37 minutes \\
\hline Temperature Range & $-88^{\circ} \mathrm{C}$ to $58^{\circ} \mathrm{C}$ & $.38 \mathrm{~g}$ \\
\hline Atmospheric Pressure & $1013 \mathrm{mb}($ avg.) & $-127^{\circ} \mathrm{C}$ to $17^{\circ} \mathrm{C}$ \\
\hline Atmospheric Gases & $78 \% \mathrm{~N}_{2}, 21 \% \mathrm{O}_{2}$ & 7 mb (avg.) \\
\hline Number of Moons & 1 (Luna) & $95 \% \mathrm{CO}_{2}$ \\
\hline Polar Ice Caps & Water Ice & 2 (Phobos \& Deimos) \\
\hline Largest Canyon & The Grand Canyon & Water Ice \& Dry Ice $\left(\mathrm{CO}_{2}\right)$ \\
\hline Highest Point & $\begin{array}{l}\text { Mount Everest }-8.848 \mathrm{~km} \\
\text { above sea level }\end{array}$ & $\begin{array}{l}\text { Valles Marineris }- \\
\text { Width of continental } \mathrm{U}_{\text {.S. }}\end{array}$ \\
\hline Lowest Point & $\begin{array}{l}\text { Marianas Trench }-11.022 \mathrm{~km} \text { Mons }- \text { Tallest } \\
\text { deep }\end{array}$ & $\begin{array}{l}\text { Hellas Basin }-4 \text { km below } \\
\text { Martian average }\end{array}$ \\
\hline
\end{tabular}

Table 1. Planetary comparisons between Earth and Mars.

Given these extremes and constraints, it is important for any future expedition to identify and budget for the resources it will have available upon arrival. To build a permanent habitation, a settlement expedition will have the tools and equipment aboard the arriving spacecraft (most likely several vehicles, some arriving before the crew), local materials (meaning the land, water, and atmospheric components of the planet Mars), and the human beings and robots making up the crew of the settling expedition.

\section{A. Imported Resources}

For the purposes of the original study, the team estimated a total arrival mass of 250 metric tons (tonnes) of cargo. Within this mass will be:

- Labor-both human and robotic_required to perform the work.

- Temporary living quarters, life support, and food necessary to support that labor until a permanent habitat is established. The study team assumed a construction crew of 12 people to construct the first permanent settlement for 12 people.

- Power System - including three nuclear reactors providing up to $400 \mathrm{~kW}$ of electrical power and the components needed to distribute that power throughout the settlement.

- Construction Equipment. 
- Initial Mining, Refining, \& Manufacturing Equipment—-to make gases, chemicals, metals, plastics, ceramics, masonry, glass out of the local atmospheric and regolith materials at hand. In some cases, the manufacturing equipment can be bootstrapped to make more capable manufacturing equipment.

- Other high-tech / low mass items or items that would be difficult to manufacture initially on Mars - such as sensors, computers, cameras, radios, other electronics, bearings, precision tools, small valves, medicines, medical devices, and small highprecision mechanical devices.

- Anything that can be scavenged from the Mars landing systems, including control systems, wiring, actuators, sensors, nylon from parachutes, sheet metals, tanks, etc.

\section{B. Local Resources}

The “mining” equipment for the first Mars settlement must also include air miners that will ingest gasses from the Martian atmosphere, which consists of $95.3 \%$ carbon dioxide $\left(\mathrm{CO}_{2}\right), 2.7 \%$ nitrogen $\left(\mathrm{N}_{2}\right), 1.6 \%$ argon $(\mathrm{Ar}), 0.15 \%$ oxygen $\left(\mathrm{O}_{2}\right)$, and $0.03 \%$ water vapor $\left(\mathrm{H}_{2} \mathrm{O}\right)$ at a pressure around 7 mbar. After collecting this material, the air miners will use standard, existing chemical processes to create oxygen, habitat buffer gases $\left(\mathrm{N}_{2} / \mathrm{Ar}\right.$ mix), methane $\left(\mathrm{CH}_{4}\right)$ and $\mathrm{H}_{2}$ fuel, longerchain hydrocarbons, and plastics (including epoxy). Depending on availability in the local ground and atmosphere, Martian water also could used to nourish plants in the settlement's greenhouse. In addition to air mining, a similar process will be performed with available local resources in the Martian rock and regolith through ore beneficiation, that is, the crushing and separating ore into valuable substances or waste by any of a variety of techniques. ${ }^{2}$

\section{The Settlement Cityscape}

Mining, of course, is only the first step in building the settlement. Once raw materials are obtained from the ground and air, the settlement structure must be built. Due to the extreme cost of importing materials and equipment, relying on habitats brought entirely from Earth is an unsustainable strategy, unless there are revolutionary advances in transportation. ${ }^{3}$

The Mars Homestead Project drew its model for habitation from the "Linear City" model developed by Arturo Soria and Le Corbusier, as seen in Figure 2. This structure provides efficiency in transportation, infrastructure, safety, and ease of expansion. As a two-avenue structure, the "Linear City" of the Mars settlement will have separately pressurized segments with rigid or inflatable pressure vessels and regolith-supported masonry. The settlement will develop in two parallel bands. The two bands of construction will be connected at regular intervals to ensure multiple means of egress from each segment and that the loss of one segment won't cut any structures from the rest of the settlement. Because the settlement runs at the base of a hill, one of the bands will be more exposed than the other. Thus the functions that require access to the surface will be housed in pressure modules along the outer trunk, while functions that require larger spaces can be buried deeper allowing the use of masonry construction 

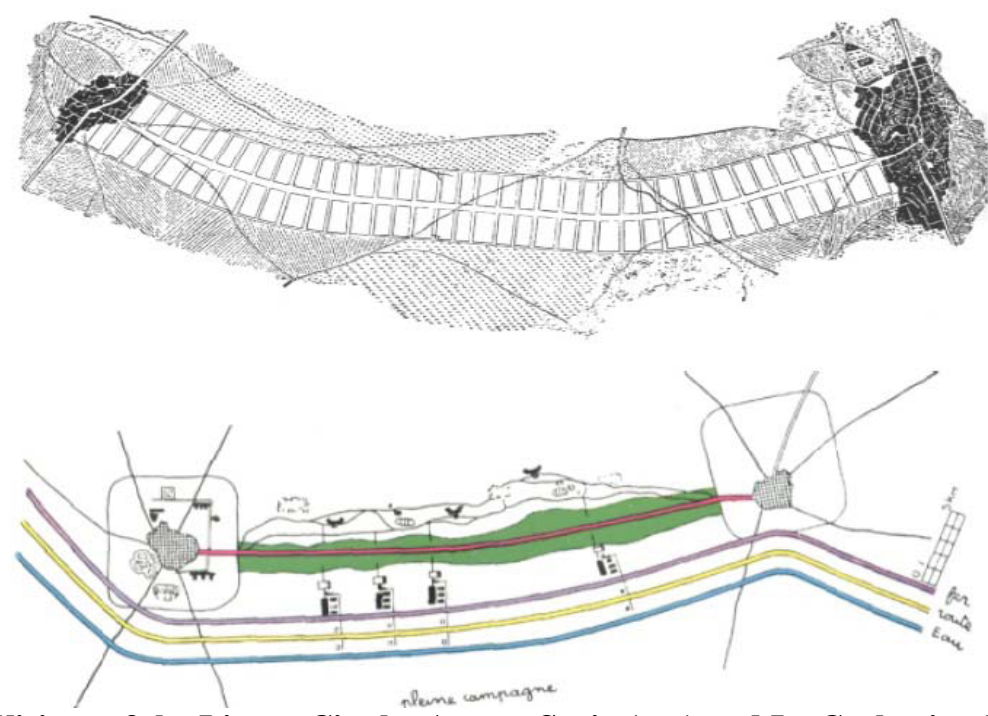

Figure 2. Visions of the Linear City by Arturo Soria (top) and Le Corbusier (bottom).

Utilities, such as air, water, and power distribution will follow the "streets" of the city in subfloor panels, as diagramed in Figures 3 and 4.

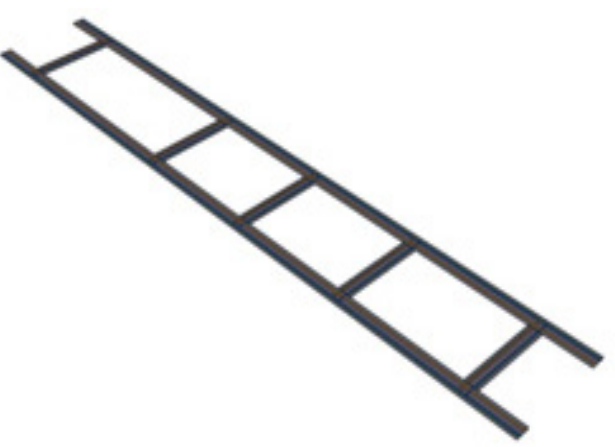

Figure 3. Diagram of planning strategy. Two bands of developments with regular connections.

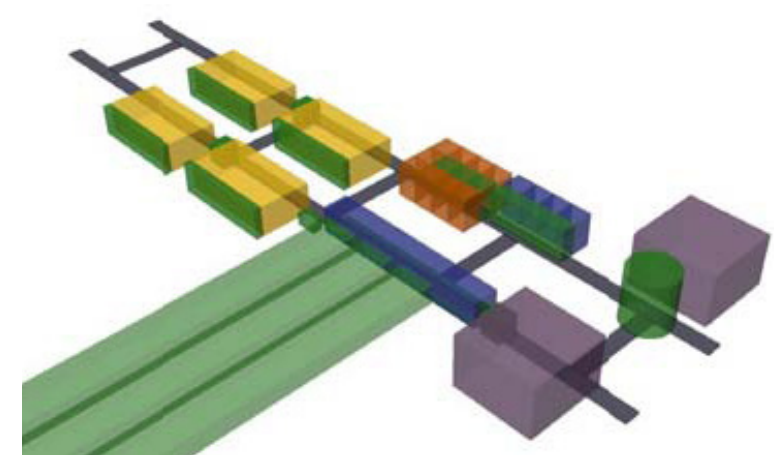

Figure 4. Habitable segments are arranged along the bands depending on they needs and interrelationships.

The early conceptual design in Figure 4 was used to evaluate the position of occupied spaces; living quarters (yellow) are adjacent to kitchen/dining/common space (brown); greenhouse (green) can be used for solitude after hours stretch into the plane in front of the settlement, manufacturing areas (purple) are far from living quarters to reduce interior noise. Work shops, greenhouse support, laboratories (blue) are located just off the circulation providing a variety of spaces for concentrated or collaborative work.

As the land is being leveled for the structures, the settlers will use the excavated regolith (dirt) as raw material to make the brick, glass, and metal construction materials for their new home. The emphasis of this settlement will be on using local materials as much as possible to complete construction of a habitat. ${ }^{4}$ Continuing to rely on habitats brought from Earth is an unsustainable strategy unless truly revolutionary advances in transportation technology are made. 
Therefore, settlers must maximize use of Martian materials and simple, well understood, and tested building techniques.

Antique as well as modern methods of construction would be used to build the first Mars settlement. Ancient methods of construction would include masonry work, while modern methods would rigid cylinders made by winding fiberglass, sheet metal would be used where practical, and inflatable structures with rigid internal floors and partitions.

The masonry structures would be based on bricks sintered from Martian regolith, reinforced with glass fibers if needed. If that is not practical, the masonry blocks could be made of glass, fused basalt, or cut stone. Brick manufacturing will require some 2,200 cubic meters of material, much of which can be obtained from the regolith excavated from the hill. Heat from the nuclear reactors can pre-heat the kiln needed to fire the brick, with the final temperature reached by electric heat or burning chemical fuel produced from the CO2 atmosphere. There will be two kilns of 1.5 cubic meters' capacity each, with a firing of time 8 hours. Given two batches per day and 6 cubic meters of brick being processed per day, it will take 370 days to make all of the brick required to build the settlement. Given the simplicity of this automated process, human intervention will be required only to maintain the equipment. A total of 20 man-weeks will be required for brick manufacturing. After the bricks are manufactured, the team must start assembling their new home. This will require a variety of different-sized vaults to achieve the size and comfort level required by the inhabitants.

\section{Building Better Living Spaces on Mars}

Given the known and potential unknown constraints on future human explorers, the Study members believed that it was not enough to build a survivable Martian habitat: priority was given to building pleasant, permanent habitations on or under the Martian surface. As noted earlier, the settlers will use the temporary shelter of their arriving spacecraft until construction of the first phase is completed. The sooner settlers are able to establish a homelike environment for themselves, the sooner we can save costs by avoiding the return flights. Also, a permanent base can easily support scientific exploration, while leading to the true goal of settlement for large numbers of people, with animals and plants.

\section{A. Vision - The Hillside Base}

The Mars Homestead Project team designed a partially underground, partially exposed facility built largely from local materials. Using a combination of imported and local resources, the Hillside Base will be approximately $90 \%$ self-sufficient by mass and will provide the settlers with the industrial capabilities they need to explore and settle the frontier.

The team selected Candor Chasma at reference coordinates 69.95W x 6.36S x $-4.4 \mathrm{~km}$ as one likely site for the Hillside Base. This site is part of the Valles Marineris canyon complex and has been photographed extensively by the Mars Global Surveyor. It consists of a number of mesas suitable for providing shelter as well as room for expansion. The site was chosen primarily for its 
proximity to several dry riverbed-like features. It is also reasonably close to Pavonis Mons, Olympus Mons, and other features of geologic interest.

Site selection and response to the site are key design issues for the first settlement. There are a large number of engineering and logistical challenges to be considered in placing the settlement ${ }^{5}$. The settlement must be located in proximity to geologically varied regions of scientific interest. There must be easily accessible in-situ resources. Low elevation is important in order to take advantage of higher atmospheric pressure, which aids both in harvesting gases from the atmosphere and landing using parachutes. Locations near the equator offer the highest solar intensity for crops, and access to and from any orbit.

There are many architectural and urbanistic issues to consider as well. ${ }^{6}$ The first permanent habitat will be our first cut in the new frontier. It is therefore a very important step that will have an effect on the future development of the planet. A transplant of a pattern from the homeland in a model such as the "Law of the Indies" will not work. There simply won't be the resources available to impose a predetermined plan that doesn't account for local conditions. The other extreme of a completely unplanned and pragmatic approach like the one taken by North American settlers is also unrealistic. The base must react to the site within a set of guiding principles.

The site must also provide a real and perceived sense of protection. On Earth, the location of a new settlement has traditionally been dominated by considerations for defense. On Mars there are no natives to defend against, thus the need for real and psychological sense of protection is against the hostile environment. Finally, any settlement needs a symbol that the residents can identify with, a landmark that identifies the structure as home, or a sacred place that will symbolize the founding of the community.

In the years to come the Mars Foundation will continue to gather more accurate and detailed information about Mars and almost certainly a much more informed decision will be reached about the final site. For the purpose of this project, a site was chosen based on the best available information as of the fall of 2004.

\section{B. Candor Chasma}

The group of mesas in the middle of Candor Chasma fulfills many of the requirements for a successful site (Figure 5). The elevation of the floor of the canyon is almost 4,800 meters below the planetary mean offering relatively high atmospheric pressure. The walls of the canyon are about eight kilometers above the base. The panorama of the cliffs and valleys will present a beautiful view for the first settlement. Additionally the mesas themselves present an interesting sight giving the settlement an engaging view in the close range as well. There are relatively flat areas to the north and south of the mesas that can serve as landing areas, where the flight paths to and from orbit will not overfly the settlement. 


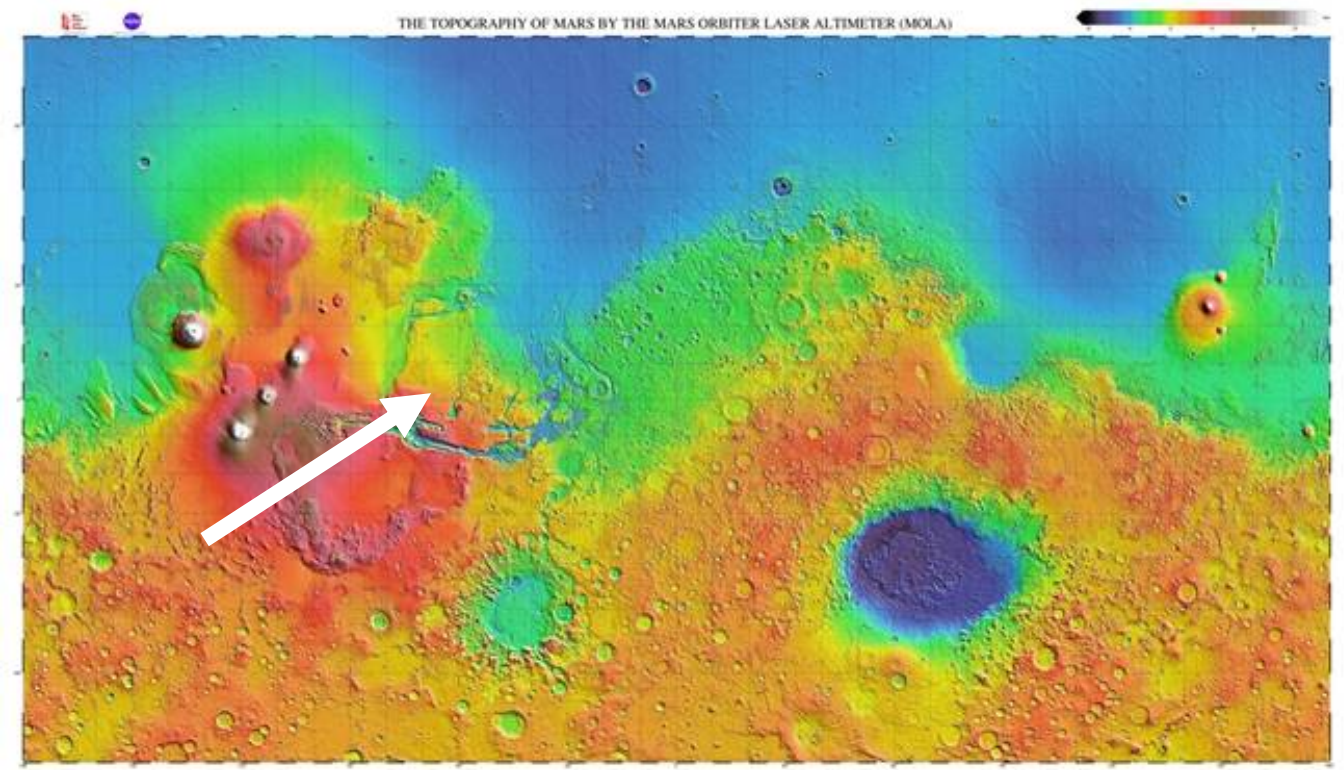

Figure 5. Hillside Base reference location.

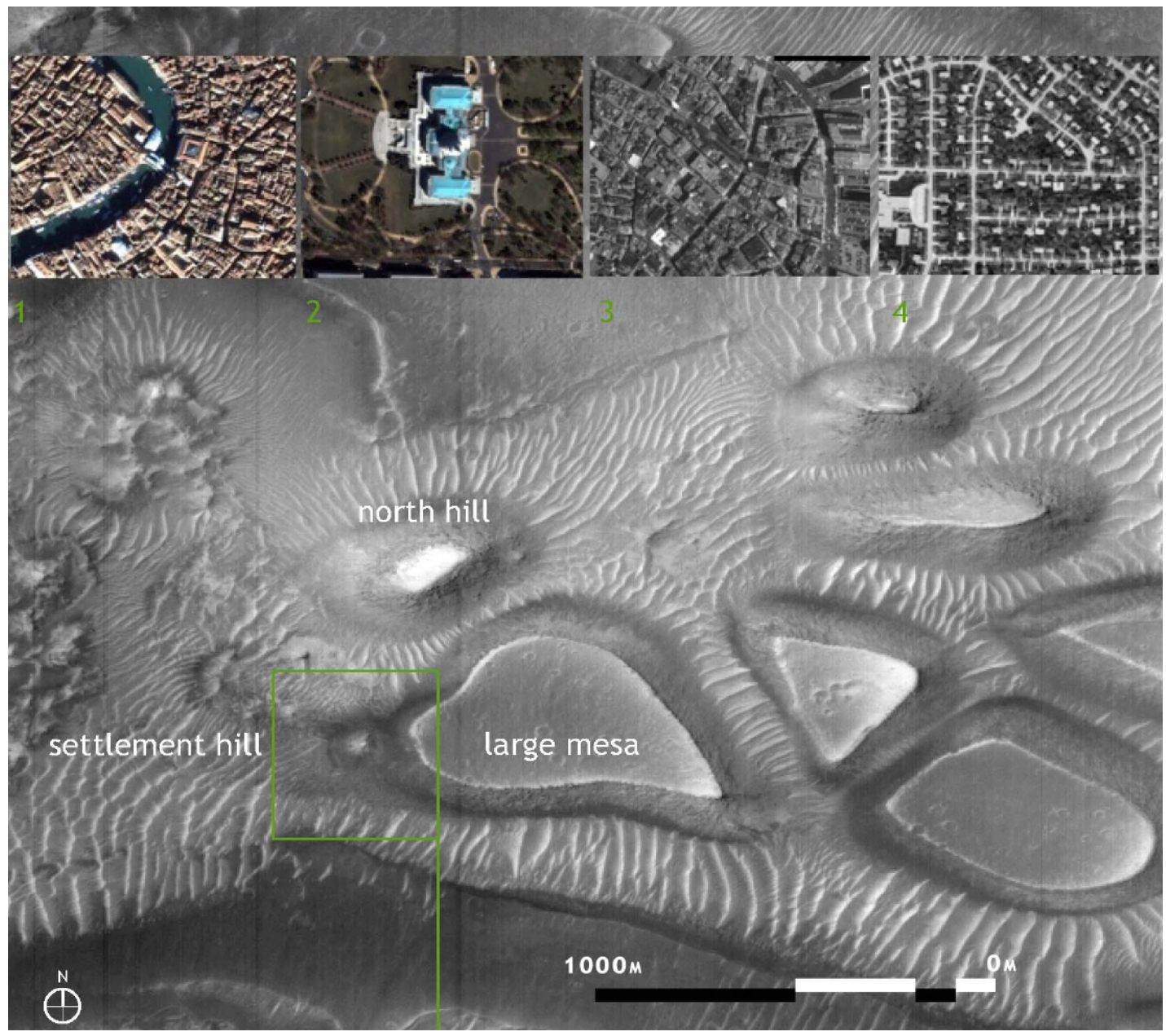

Figure 6. Possible Base location with scaled Earth city texture for comparison.

Left to right: Venice, Italy; US capitol, Washington DC; North End, Boston MA; Suburb, Champaign IL 
As seen in Figure 7, the Hillside Base reference design is quite extensive. It provides habitation for 12 people and covers 800 square meters, with greenhouses, fuel, nuclear plants, and manufacturing facilities located outside. Private living spaces, labs, and common areas are situated inside the mesa, with some of the rooms providing views of the outside.

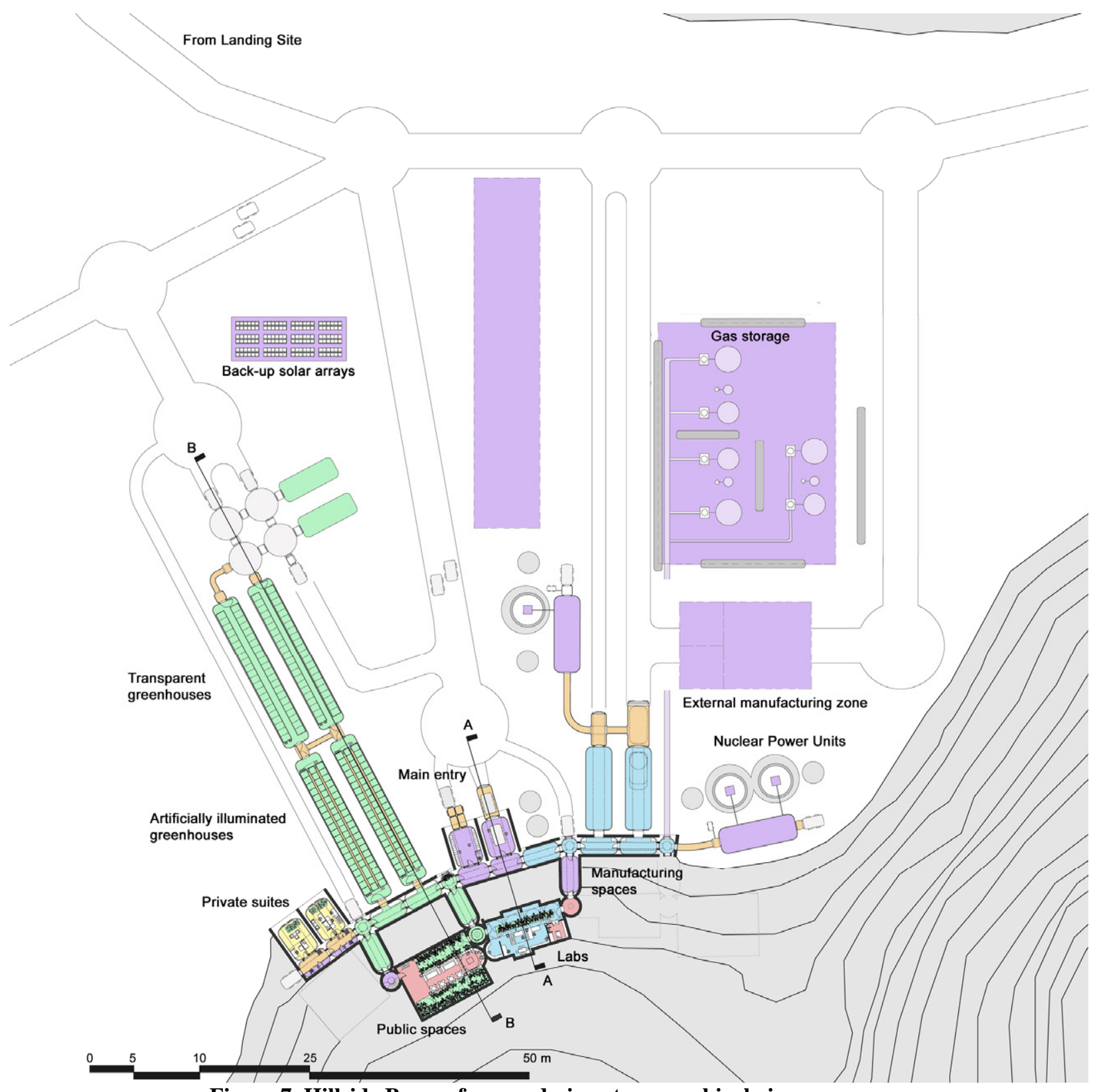

Figure 7. Hillside Base reference design--topographical view.

The base depicted in Figures 7 and 8 is a habitation for 12 people. However, Figure 9 below shows how the complex could be expanded along the mesa wall for an additional 12 people about every two and a half years. 


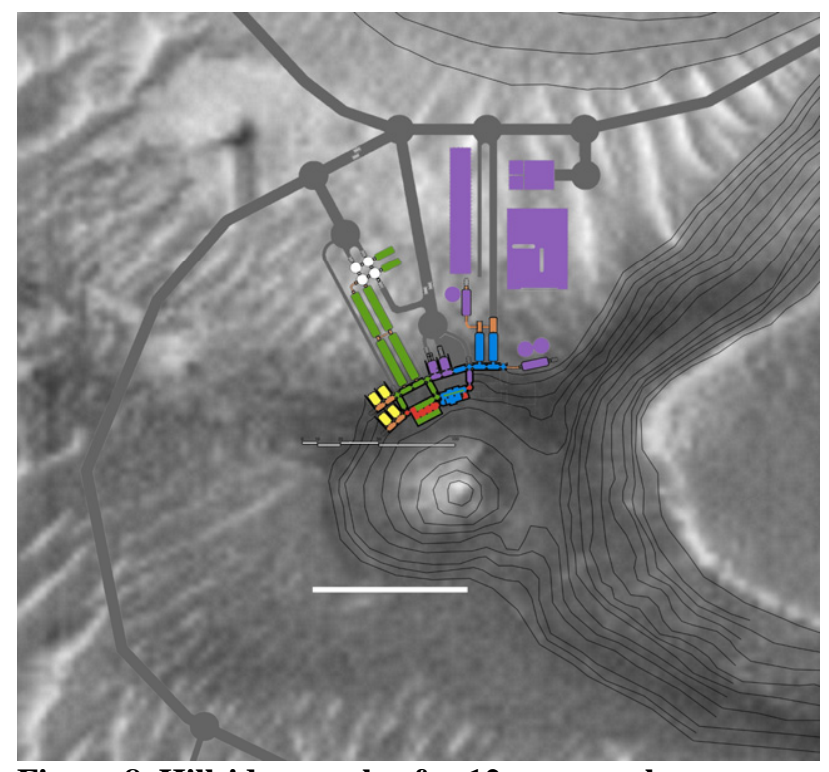

Figure 8. Hillside complex for 12 personnel

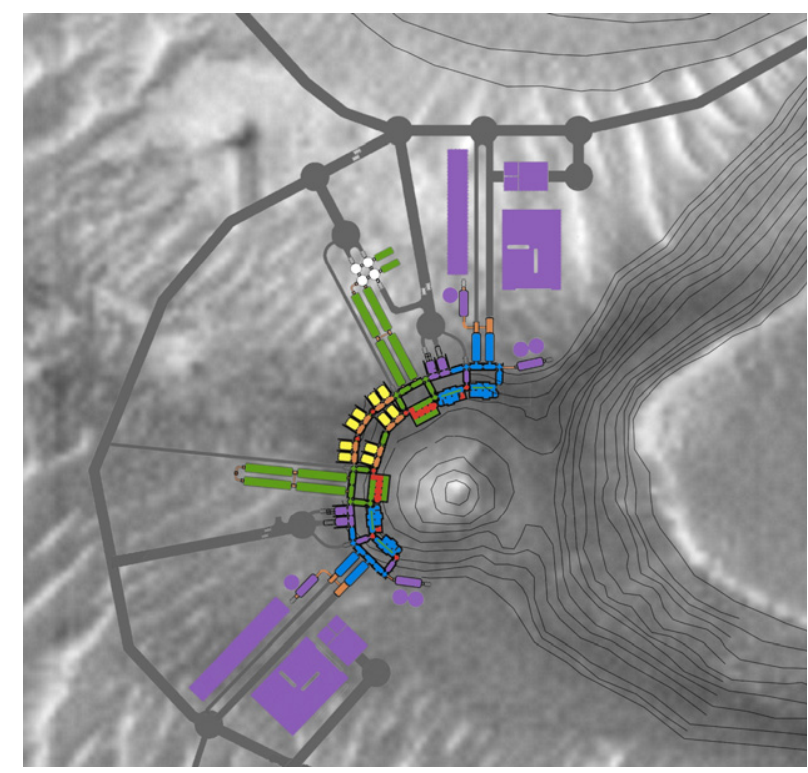

Figure 9. Hillside complex for 36 personnel

\section{Entrance}

The main entrance is composed of two pressurized modules: the main entry and a garage. The main entry module consists of two airlocks with multiple egress options. One of the airlocks will provide direct access to the Martian surface for daily exterior activities, such as construction and repair work. The other airlock will be a docking port for rovers. ${ }^{7}$

\section{Social Spaces}

The settlement will include areas for the entire group to gather in one place. These spaces are arranged along the infrastructure, with vegetation mediating the spaces between humans. The human activities are located in the center with the trees surrounding them on two sides. This is where the community comes together on a daily basis. The space includes the communal kitchen and dining areas. The two bays above the dining area are covered with two-story high barrel vaults marking this as a special subspace of the segment. The second level includes balconies, catwalks, public work spaces, and also spaces for exercise and entertainment. Figure 10 below depicts how vegetation would be used in the floor plans.

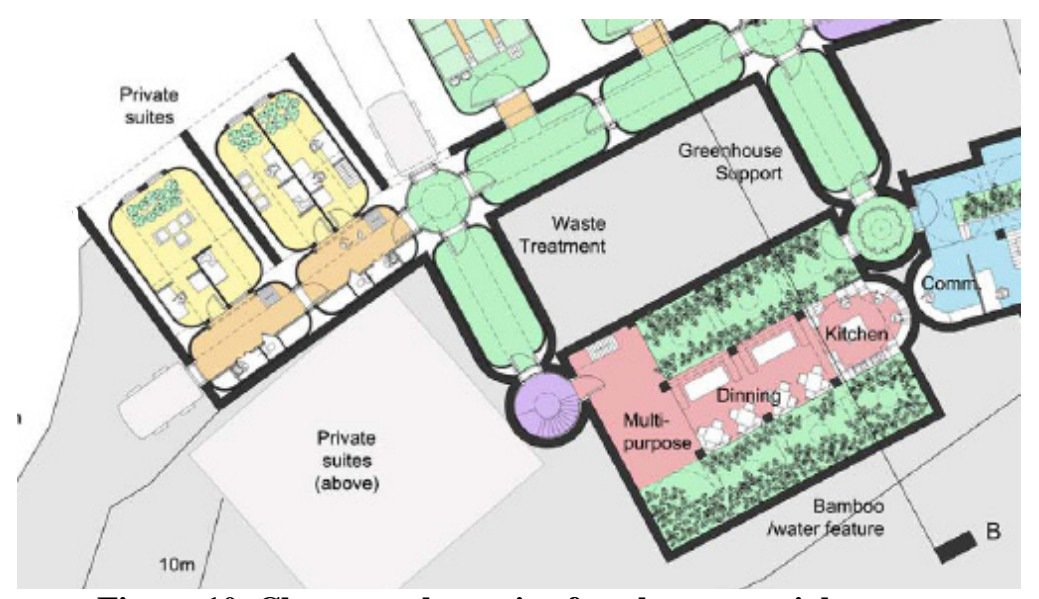

Figure 10. Close up schematic of settlement social spaces. 


\section{The Greenhouse}

The greenhouses are the largest modules of the settlement and are situated on the flat land extending away from the mesa. The greenhouses are built with redundancy in mind: if one unit fails demand can be covered by adjacent units. Each module has complete capability of cycling water, air, and nutrients. The waste handling and water purification units are in the greenhouses and their adjacent modules. Note that $100 \%$ recycling in not required, since gases, water, and minerals can be extracted from Mars air and soil. Two greenhouses are transparent, to take advantage of natural sunlight, supplemented with artificial light as needed. The other two greenhouses are opaque, covered with regolith, and artificially lit.

The crops include a variety of vegetables and grains, as well as some non-edible plants grown for their fibers or to make particle board. Initially, crops will be grown hydroponically, in trays made from local fiberglass or ceramic pots, filled with gravel. Later, we hope to grow in native soils after leaching minerals as needed and adding organic material. Additionally, since some residents plan to spend the remainder of their lives here, the greenhouses are deliberately designed for long sight lines, walking, jogging, or for solitude after work hours.

\section{Using Vegetation as a Fundamental Aspect of Settlement Life}

Internal vegetation will be an integral part of the Mars settlement's social structure and sustainability, as it will be used as a symbol, life support component, mediator of exterior views, green belt for breaking up social spaces, and overall mediator of social life. ${ }^{8}$

As a symbol, vegetation will hold a special place immediately between the main entrance and the formal meeting space, as the settlers will plant trees on arrival. These plants will symbolize hope and the permanence of the settlement. The trees will grow as the settlement expands, and when people arrive from Earth, the first thing they'll see as they enter is the grove of trees. They wouldn't mind an occasional fruit or nuts from the trees, as well.

As a life support component, plant-rated greenhouses will optimize atmosphere, light, structure and safety for specially designed plants. The farmers will plant seedlings and harvest the crops from inside a pressurized area with the aid of robots.

As a mediator of views within the settlement structure, plants will be placed in front of any windows to the outside, allowing settlers to look at the red of Mars through the soothing green of Earth vegetation. Additionally, every private suite has a small garden area in front of its window and connector segments will terminate with small gardens and a window onto Mars. As a green belt, vegetation will separate heavily traveled areas from work spaces.

As a mediator of social life, plant life will be located at the center of social spaces. The various social spaces are arranged around the periphery and every space looks at the others through the vegetation. The trees provide much-needed change in the underground space.

As part of the "clearing in the woods" in the central social area, plants will play an important part of the "Chinese garden" social space surrounded and protected by trees. The edges of the space will be hidden, thus obscuring the limited size of the space. Pocket gardens will provide focused diagonal views between social spaces as well. ${ }^{9}$ 


\section{Other Humanizing Features}

In addition to plants, the overall settlement structure will be laid out with human psychology in mind, as it will feature social "spaces" to cover the entire range of human experiences, from the individual, to couples, to informal subgroups, formal subgroups, and the entire community. Figure 11 below, by Phil Smith, depicts the large, open, multi-story masonry structures which are located deep within the hillside. Natural sunlight is directed into this area from lightpipes above. A Mars settler leans on the bamboo rail and takes in the view, which includes some lush green spaces.

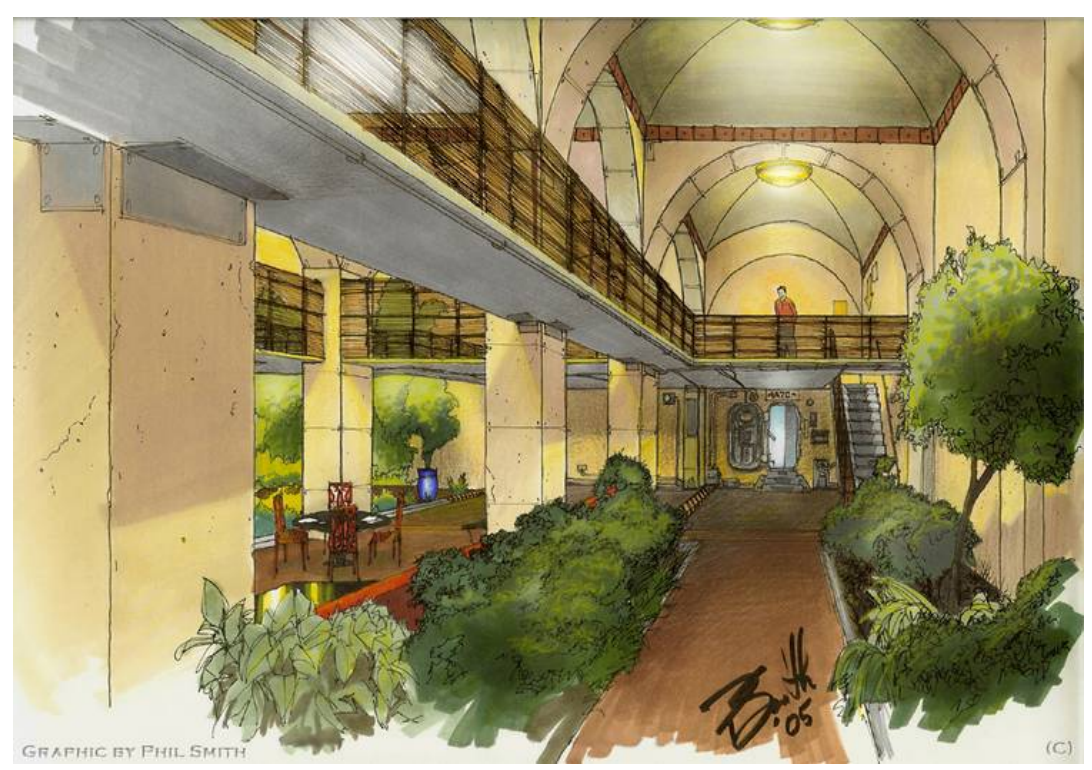

Figure 11. Depiction of two story common area, by Phil Smith.

As life in our urban society has shown, artificial lighting is not enough to meet human needs. Therefore, the domes where vegetation is housed have shafts that reach to the surface, as shown in Figure 12, below. There, light is collected by lenses and brought down to an opening in the top of the dome where it is spread out again by another lens.

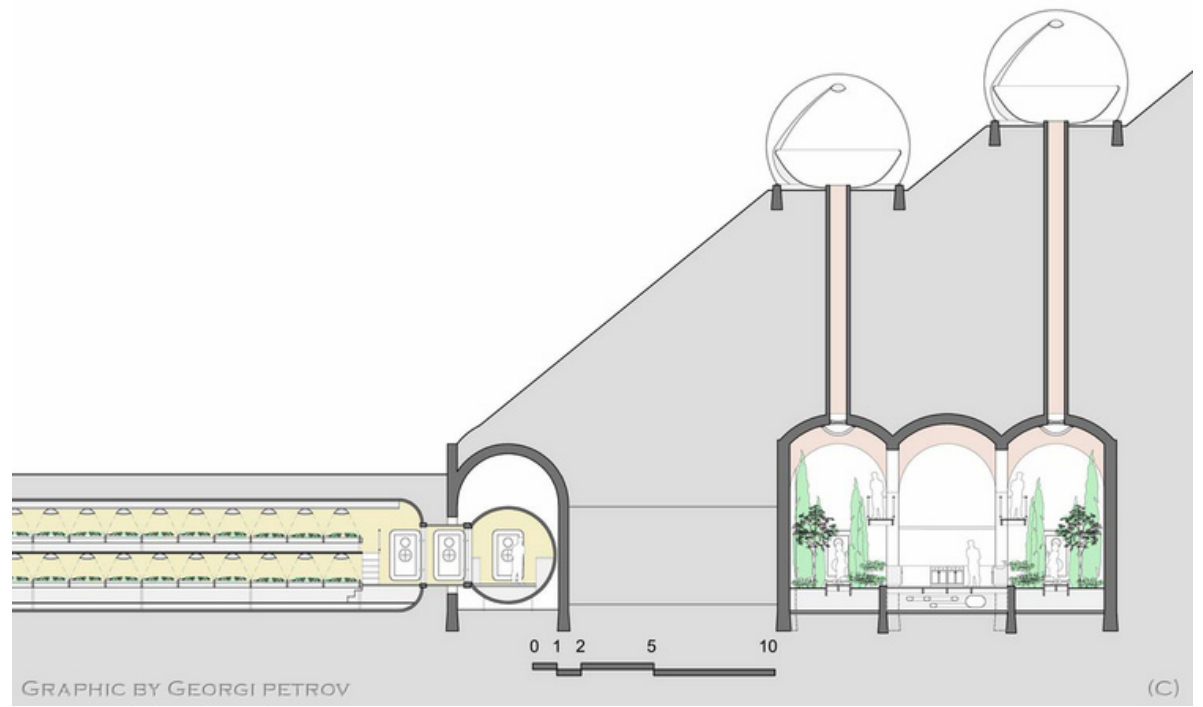

Figure 12. Cut-away view, greenhouse on left, shallow masonry covering inflatable in center, deeply buried two story masonry on right, light collectors in upper right. 


\section{Pressurized Construction}

Figure 12 is also a good comparison of different construction techniques to handle the internal air pressure. Rigid cylinders are used in the flat, open areas away from the hillside. The smaller, standard size rigid modules would be wound fiberglass, constructed inside an inflatable construction tent. The larger ones must be sheet metal welded on-site. Most would be covered with at least 1 meter of regolith to provide minimal radiation protection. These modules are at the left on figure 12, and top of figure 7. They include: the private suites, greenhouses greenhouse support spaces, nuclear power 'balance of plant' in purple, the airlock support spaces, and some manufacturing spaces.

Buried Masonry vaults and domes are used for much of the living space. We excavate into the hillside in the loose talus slope, and build the vaults there. To hold the internal pressure, between six and ten meters of regolith (depending on composition and level of compacting) must be placed over them. Obviously, the masonry must be strong enough to hold the weight of the overburdened, and have buttresses shaped to hold the weight whether they are pressurized or depressurized. To keep the air from leaking, the bricks are glazed and caulked on the inside. In addition, alternating layers of sand and vapor barrier are placed outside the masonry to collect air which does leak, and suck it back into the air processing equipment to be recovered. These modules are at the bottom of figure 7 shown with thick walls, and at the right on figure 12 . They include the: two-story public space, labs, kitchen, dining area.

Masonry over Inflatables are used at the edge of the hillside, to transition from the deeply buried masonry vaults to the open area. These are simple inflatable cylinders made from thinner fiberglass or cloth or thin sheet metal. They are used inside masonry vaults to protect them. The masonry also holds the hillside back and provides radiation protection. These modules are at the middle of figure 7 shown as thick walls with rounded lines inside them, also at the middle of figure 12. They include the: private suites, waste treatment, greenhouse support, main entry, suit room, rover garage, and some manufacturing spaces.

\section{Joining the Mars Homestead Project}

The Mars Homestead Project can use volunteer help, and also material donations and financial assistance, to keep projects like this viable. The Mars Foundation manages a number of task forces and sub-projects to continue and further articulate its Earth-based studies of a future Mars settlement. These task forces include:

- Mission Planning

- Safe Haven Design

- Large Module Design

- Economic Analysis

- Site Selection

- Vehicles

- Robotics and Automation

- Polymer Synthesis 


\section{A. Prototype Projects}

The Foundation can sponsors prototype projects, which are small projects suitable for local groups, students, university classes. These projects would design or select equipment to facilitate a self-sustaining settlement on Mars. Such activities could include:

- Furniture Manufacture

- Kitchen equipment

- Inflatable structures

- Masonry structure

- Table top process demos

- Miniature plastics moulding

- Miniature machine shop equipment

- Recycle spacecraft hardware

- Clothing from parachutes

- Felt \& paper manufacture
- Metal Refining

- Surface Vehicles

- Robotic assistants

- Flexible chemical equipment

- Gas separation equipment

- Fiberglass winding

- Brick laying robots

- Portable power supplies

- Mars Cookbook

- Explosives

Table 2. Potential future projects.

Other activities include greenhouse experiments, outfitting a single module of the proposed settlement, or developing small robotic projects.

\section{B. Test and Demonstration Center}

The Mars Foundation is considering a demonstration and research site, to study technologies needed for Mars construction. This facility would publicly demonstrate the feasibility and advantages of early, low-cost, permanent settlement of Mars. It would engage in publicity, education, and public involvement efforts, many geared especially to children.

This outreach center would:

- Integrate research equipment

- Research building techniques using Martian materials

- Research semi-closed biological life support

- Research automated food processing
- Hold Edutainment contests

- School tours, special programs, children's camp, etc.

- "Living History" community (Plymouth, Sturbridge)

- Apply lessons learned to Earth ecology

- Change the public mindset

Mars Homestead and Mars Foundation are trademarks of the Mars Institute incorporated in Massachusetts, USA, dba. Mars Foundation.

We can be reached at: Info@MarsHome.org www.MarsHome.org 


\section{Conclusion}

The Mars Foundation's Mars Homestead Project shows a cost-effective, human-friendly first settlement for Mars. Compared to round-trip missions, we avoid the risk and cost of most of the return flights, and use the saving to send construction equipment. The refining equipment produces fiberglass, masonry, plastics, and metal construction materials. Semi-automated manufacturing equipment assembles the habitats, laboratories, and greenhouses for permanent use. Thus, we can afford to build a permanent, growing base to both support scientific study, and immediately start settlement. This would cost about the same as three round trip missions, such as the NASA Design Reference Missions (DRM). The Foundation strongly encourages interested attendees of the Space 2006 Conference to join the Mars Homestead project, or suggest complementary projects.

\section{Acknowledgements}

This Hillside Base and other Mars Homestead work was done by an extended team, including: April Andreas, James Burk, Frank Crossman, Robert Dyck, Damon Ellender, Gary Fisher, Inka Hublitz, Mark Homnick, Bruce Mackenzie, K. Manjunatha, Joe Palaia, Georgi Petrov, Richard Sylvan.

\section{References}

${ }^{1}$ Images courtesy of Georgi Petrov, 4Frontiers, Mars Foundation, and/or NASA

${ }^{2}$ Wordnet.Princeton.edu. http://wordnet.princeton.edu/perl/webwn?s=beneficiation.

${ }^{3}$ Petrov, Georgi I., Bruce Mackenzie, Mark Homnick, and Joseph Palaia IV. A Permanent Settlement on Mars: The Architecture of the Mars Homestead Project. Society of Automotive Engineers (SAE) International, 2005.

${ }^{4}$ Mackenzie, Bruce, "Building Mars Habitats Using Local Materials” pg 575 in The Case for Mars III: Strategies for Exploration. Stoker, Carol ed., American Astronautical Society: Science \& Technology Series v74, 1987. ${ }^{5}$ James G., G. Chamitoff, D. Barker, "Resource Utilization and Site Selection for a Self-Sufficient Martian Outpost.” NASA/TM-98-206538. 1998.

${ }^{6}$ Petrov, Georgi. A Permanent Settlement on Mars: The First Cut in the Land of a New Frontier. Master of Architecture Thesis, MIT 2004.

${ }^{7}$ Petrov, Georgi I., Bruce Mackenzie, Mark Homnick, and Joseph Palaia IV. A Permanent Settlement on Mars: The Architecture of the Mars Homestead Project. Society of Automotive Engineers (SAE) International, 2005.

${ }^{8}$ Alexander, Christopher, A Pattern Language. Oxford University Press, 1977. ISBN 0-19-501919-9.

${ }^{9}$ Ibid. 